\title{
Impact of Pasteurization Process on the Quality and Marination Properties of Onion Juice
}

\author{
Hande Demir ${ }^{1, a, *}$, Mustafa K. Yıldız ${ }^{1, b}$, İsmail Becerikli ${ }^{1, c}$, Sevcan Unluturk ${ }^{2, d}$, Zehra Kaya ${ }^{2, e}$ \\ ${ }^{1}$ Department of Food Engineering, Osmaniye Korkut Ata University, 80010 Osmaniye, Turkey \\ ${ }^{2}$ Department of Food Engineering, İzmir Institute of Technology, 35430 Urla/İzir, Turkey
}

*Corresponding author

\begin{tabular}{l|l}
\hline A R T I C L E I N F O & A B S T R A C T \\
\hline Research Article & $\begin{array}{l}\text { This study aims to compare UV-C irradiation and conventional heat treatment to produce pasteurized } \\
\text { onion juice used as a meat marinating agent. The process conditions maximizing the inactivation of } \\
\text { target microorganism Escherichia coli } \mathrm{K}-12 \text { were; } 0.5 \mathrm{~mm} \text { sample depth, } 30 \mathrm{~min} \text { irradiation, } 7.5 \\
\mathrm{~mW} / \mathrm{cm}^{2} \mathrm{UV} \text { incident intensity for UV-C and, } 74.5^{\circ} \mathrm{C} \text { and } 12 \mathrm{~min} \text { for heat treatment. Except } \mathrm{pH} \text { and } \\
\text { non-enzymatic browning index, differences between physicochemical properties of raw, UV-C and } \\
\text { heat-treated onion juices were significant. Springiness and chewiness of unmarinated beefsteaks } \\
\text { Accepted : 04/02/2020 } \\
\text { were higher compared to the ones marinated with the fresh and pasteurized onion juice (UV-C and } \\
\text { heat). Pasteurization of onion juice (UV-C and heat) did not significantly affect general liking scores } \\
\text { compared to beefsteaks marinated in untreated onion juice. }\end{array}$ \\
Keywords: &
\end{tabular}

Keywords:

Onion juice

UV-C irradiation

Heat treatment

Meat marination

Response surface methodology

hande.genckal@gmail.com ismailbecerikli@gmail.com e@zehraky86@gmail.com

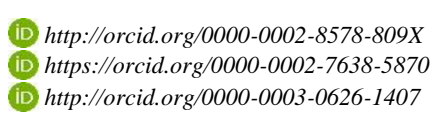

b@mustafakemalyldz@gmail.com d@sevcanunluturk@iyte.edu.tr

D https://orcid.org/0000-0001-8578-2387

iD http://orcid.org/0000-0002-0501-4714

(c) () () (9) This work is licensed under Creative Commons Attribution 4.0 International License

\section{Introduction}

Onion (Allium cepa) ranks third in the world production among seven major vegetables (onion, garlic, cauliflower, green pea, cucurbit, tomato, green bean) (Mitra et al., 2012). It is one of the most consumed vegetables both in European (especially in England, Holland and Spain) and Asian (China, India and Japan) countries (Li et al., 2016) with the Asian production share of $62.9 \%$ (FAOSTAT, 2017). $20 \%$ of the produced onion was discarded as waste in European countries mainly in the UK, Holland, Italy and Spain (Gonzalez-Saiz et al., 2008). In recent years, thanks to its underlined positive health effects and popularity in ethnic cuisines, the consumption of onion has been increased by $25 \%$ worldwide. Onion juice (OJ) is one of the products that can add value to these surplus onions which has use as; marinating agent for fish and meat marination, flavoring sauce and component of some blended vegetable juices after the assurance of food safety
(Demir et al., 2018). Currently, many of the large-scale processed meat producers prefer to marinate the meat directly in the onion juice or in a sauce formulation including onion juice.

Low-acid $(\mathrm{pH}>4.6)$ vegetable juices, such as onion juice (pH: 5.0 - 5.5) require high-temperature (above $100^{\circ} \mathrm{C}$ ) sterilization to prevent the product from spoilage. On the other hand, to reduce the negative effect of high temperature on the sensory and nutritional quality of vegetable juices, acidification $(\mathrm{pH}<4.6)$ of juice by an organic acid is commonly preferred that enables use of pasteurization (below $100^{\circ} \mathrm{C}$ ) norms (Wu and Chen, 2011). Therefore, in this study, onion juice was acidified $(\mathrm{pH}<4.6)$ using citric acid to allow pasteurization as previously applied to carrot juice (Ferrarioet al., 2017). However, studies showed that even pasteurization at mild temperatures may cause problems such as discoloration, 
off-flavor or off-taste formation or loss of vitamin in juices (Tran and Farid, 2004). At this point, non-thermal processing of juices emerged as alternative processing methods. Among these methods, UV-C irradiation, which has germicidal effect on microbial populations, gained the attention as a pasteurization process for onion juice due to its previously reported minimal negative impact toward quality of products (Shahet al., 2016). UV-C (200 - 280 $\mathrm{nm})$ light being a part of UV band $(100-400 \mathrm{~nm})$ is absorbed by genetic material of the cell resulting in mutagenic and cytotoxic lesions in DNA. However, depending on the UV processing dose and specific nutrients, UV light was reported to have varying effect on nutritional, enzymatic and physicochemical properties of juice which should not be overlooked (Turtoi and Borda, 2013).

The increased resistance of some strains of pathogenic Escherichia coli $\mathrm{O} 157: \mathrm{H7}$ to the acidic fruit juices was reported to cause outbreaks even after pasteurization (Koutchma et al., 2016). Therefore, E. coli K-12 (ATCC 25253), a surrogate of E. coli O157:H7 was selected as the target microorganism to investigate the optimum microbial inactivation conditions that pasteurize acidified onion juice.

The objective of this study was to assess the use of conventional heat treatment and UV-C irradiation techniques for the processing of pasteurized onion juice regarding its microbiological and physicochemical quality. In addition, effect of heat treatment or UV-C irradiation on marination power of onion juice were revealed by determining the sensorial and textural attributes of the onion juice-marinated meat.

\section{Materials and Methods}

\section{Preparation of $\mathrm{OJ}$}

Mature, yellow and undamaged onions (Allium cepa L.) with approximately $10 \mathrm{~cm}$ body diameter were purchased from wholesale market hall of Osmaniye, Turkey. After hand peeling, onions were washed with tap water and dried by paper towel. Onion juice was extracted by a home-type juice extractor (Braun J700) and centrifuged (Hettich Universal $320 \mathrm{R}$ ) at $+4^{\circ} \mathrm{C}$ and $3000 \mathrm{rpm}$ for $15 \mathrm{~min}$ and supernatant was acidified using 10\% (w/v) citric acid (ACS grade, Merck) until it reaches $\mathrm{pH} 4.3$.

\section{Microbial Analyses}

A loopful of $E$. coli K-12 strain was transferred from $80^{\circ} \mathrm{C}$ glycerol stocks into $10 \mathrm{~mL}$ enrichment medium (Merck Nutrient Broth) and incubated overnight at $37^{\circ} \mathrm{C}$. E. coli $\mathrm{K}-12$ was gradually adapted to $\mathrm{pH} 4.3$ using citric acid as described in (Uysal Pala et al., 2013). To inoculate the onion juice samples, cells were prepared by transferring $100 \mu \mathrm{L}$ from the enrichment medium into $100 \mathrm{~mL}$ tryptic soy broth with $0.75 \%$ glucose in $250 \mathrm{~mL}$ Erlenmeyer flasks incubated at $37^{\circ} \mathrm{C}$ overnight and harvested by centrifuging at $3000 \mathrm{rpm}$ for $5 \mathrm{~min}$ and suspended with $1 \mathrm{~mL}$ sterile buffered peptone water. Background microflora of onion juice prepared as $100 \mathrm{~mL}$ batches in Pyrex bottle was eliminated by pasteurizing at $65^{\circ} \mathrm{C}$ (internal temperature) for 2 min using a water bath (JP Selecta). Suspended E. coli $\mathrm{K}-12$ cells were inoculated into the pasteurized and cooled onion juice $\left(10^{6-7} \mathrm{cfu} / \mathrm{mL}\right)$. Enumeration was done as described in (Unluturk et al., 2008) by surface plating on tryptic soy agar in duplicate.

\section{Determination of Production Conditions for Pasteurized OJ \\ $U V-C$ irradiation of $O J$}

Apparatus is equipped with two pairs of $20 \mathrm{~W}$ low mercury UV lamps (Mineralight, UVP XX-20) at $254 \mathrm{~nm}$ wavelength and orbital platform shaker (IKA KS 260) placed on a sliding flat platform to adjust distance of the sample to the light source. Samples in Petri dishes covered with a cylindrical black tube were placed under UV light source and shaken at $50 \mathrm{rpm}$. A radiometer (UVP Inc. UVX) with UVX-25 sensor was used by placing at a similar distance as the onion juice samples. The apparatus was disinfected using $70 \%$ (v/v) ethanol solution and UV lamps were opened at least $30 \mathrm{~min}$ before treatment. The depth of the sample was calculated from the ratio of the sample volume and the surface area of a Petri dish (Demir et al., 2018).

\section{Conventional heat treatment of $O J$}

Heat treatment was performed by placing capped test tubes filled with $9.8 \mathrm{~mL}$ onion juice into water bath. A Ktype thermocouple replaced in one of the test tubes was used to monitor cold spot temperature. As the target temperature reached, $0.2 \mathrm{~mL}$ E. coli $\mathrm{K}-12$ suspension was inoculated and shook during the treatment time. Following the heat treatment, tubes were cooled to room temperature by immediately immersing into ice-bath (Demir et al., 2018).

\section{Physicochemical Analyses}

Absorbance coefficient $\left(\mathrm{cm}^{-1}\right)$ was determined according to (Unluturk \& Atilgan, 2014). Density (g/ $\mathrm{cm}^{3}$ ) of the onion juice samples were measured by a digital density meter (Kyoto DA650) at $20^{\circ} \mathrm{C}$. Total soluble solids content $\left({ }^{\circ} \mathrm{Bx}\right)$ of the juice samples was measured by a digital refractometer (Krüss DR6000) at room temperature. Turbidity was measured by turbidimeter (HACH 2100N). Samples were filled into quartz glass containers and immediately inserted into the instrument after turning upside down for 3 times. Results were given as nephelometric turbidity unit (NTU). CIE $L^{*}$ (lightness), $a^{*}$ (redness) and $b^{*}$ (yellowness) colour parameters were determined in triplicate using a chromometer (Konica Minolta CR 400 Chromometer). Total colour change $(\Delta \mathrm{E})$ values of the samples were calculated by Eq. 1 and untreated onion juice was taken as the reference.

$$
\Delta E=\sqrt{\left[\left(\mathrm{L} *-\mathrm{L}_{\mathrm{ref}}\right)^{2}+\left(\mathrm{a} *-\mathrm{a}_{\mathrm{ref}}\right)^{2}+\left(\mathrm{b} *-\mathrm{b}_{\mathrm{ref}}\right)^{2}\right]}
$$

$\mathrm{pH}$ of the juice samples was measured by a $\mathrm{pH}$ meter (Hanna HI 2211) at $25^{\circ} \mathrm{C}$. Total titratable acidity of the samples was determined and calculated according to Demirdöven (2009) and expressed in \% anhydrous citric acid (ACA). The non-enzymatic browning index (NEBI) was determined by adding $5 \mathrm{ml}$ of ethyl alcohol to $5 \mathrm{ml}$ of sample, centrifuging for $20 \mathrm{~min}$ at $800 \mathrm{~g}$ and the absorbance of the supernatant was read at $420 \mathrm{~nm}$ in a spectrophotometer. Total phenolic content of the onion juice samples was analyzed according to Sun, Powers, \& Tang (2007) using Folin-Ciocalteau colorimetric assay. 


\section{Meat}

Texture Profile Analysis and Sensorial Evaluation of

Meat from the loin part of the beef with an average thickness of $1.3 \mathrm{~cm}$ were marinated in untreated (freshly prepared), UV-C $(0.5 \mathrm{~mm}$ sample depth, $30 \mathrm{~min}$ irradiation, $7.5 \mathrm{~mW} / \mathrm{cm}^{2} \mathrm{UV}$ incident intensity) or heat $\left(74.5^{\circ} \mathrm{C}, 12 \mathrm{~min}\right)$ treated onion juice for overnight at refrigerator temperature. Following the marination, marinated beefsteaks and raw beefsteak (after reaching room temperature) as the negative control were analyzed for their texture profile using Brookfield CT3 Texture Analyzer. A cylindrical probe $(12.7 \mathrm{~mm})$ was used and texture profile analysis test was applied. The probe speeds were of $3.0 \mathrm{mms}^{-1}$ (pre-test), $1.0 \mathrm{mms}^{-1}$ (test) and $3.0 \mathrm{mms}$ 1 (post-test). Deformation rate was $75 \%$ of the sample thickness during the test. For each meat sample, the test was repeated in triplicate.

The marinated and unmarinated meat samples were grilled on an electrical grill for $5 \mathrm{~min}$ after the core temperature reached $75^{\circ} \mathrm{C}$. Grilled meat was evaluated by a sensory panel composed of 20 panelists of average age 24 consuming meat in their daily diet according to Gibis (2007) (hedonic scale between like very much (10) and do not like at all (0)).

\section{Experimental Design and Statistical Analysis}

Factors and their levels affecting on microbial inactivation were investigated using experimental design and statistical analysis methods performed by DesignExpert 7.0.0 (Stat-Ease Inc.) software and summarized in Table 1. Face-centered central composite design (FCCD) was used for optimization of both UV-C treatment and heat treatment pasteurization conditions. Significance level was 0.05 for the $P$-value. UV-C incident intensity was kept at $7.5 \mathrm{~mW} / \mathrm{cm}^{2}$ and levels of the investigated factors were determined as a result of screening study (data not shown). Logarithmic reduction in the $E$. coli $\mathrm{K}-12$ count $(\mathrm{cfu} / \mathrm{mL})$ was monitored as the response value. The results of physicochemical properties, sensory and texture profile analysis were evaluated by one-way ANOVA using Minitab software (Minitab Inc.).

\section{Results and Discussions}

Determination of $U$ V-C Treatment Conditions for Pasteurized OJ

The experimental design FCCD was used to investigate the effect of UV-C exposure time (A) and sample thickness (B) on the $\log$ reduction of $E$. coli $\mathrm{K}-12$ number. UV-C incident intensity of $7.5 \mathrm{~mW} / \mathrm{cm}^{2}$ was used as the fixed UV$\mathrm{C}$ intensity value based on the results of the previous screening study (data not shown). According to the analysis of variance (ANOVA), UV-C exposure time ( $P$-value: $0.0055)$ and sample thickness $(P$-value: 0.0148$)$ were found to have significant effects on the log reduction of target microorganism. The Lack-of-fit $P$-value of the constructed model was 0.4562 . The model equation describing the log reduction of $E$. coli $\mathrm{K}-12$ in onion juice subjected to UV-C irradiation was depicted in Eq. 2. Maximum log reduction of E. coli $\mathrm{K}-12(4.21 \log \mathrm{CFU} / \mathrm{mL})$ in onion juice was achieved when the juice samples with the depth of $0.5 \mathrm{~mm}$ were irradiated between 27 and 39 min with the applied UV dose of $6374.5 \mathrm{~mJ} / \mathrm{cm}^{2}$ (Figure 1a).
Table 1. Coded and actual levels of independent variables in fccd

\begin{tabular}{lc|lcc}
\hline \multirow{2}{*}{ Treatment } & \multirow{2}{*}{ Sign } & \multicolumn{1}{c}{ Factor } & \multicolumn{2}{c}{ Actual levels } \\
\cline { 3 - 5 } & & & $(-1)$ & $(+1)$ \\
\hline \multirow{2}{*}{ UV-C } & A & Exposure time (min) & 20 & 40 \\
& B & Sample depth $(\mathrm{mm})$ & 0.5 & 2.5 \\
\hline \multirow{2}{*}{ Heat } & $\mathrm{C}$ & Temperature $\left({ }^{\circ} \mathrm{C}\right)$ & 55 & 75 \\
& $\mathrm{D}$ & Time (min) & 4 & 12 \\
\hline
\end{tabular}

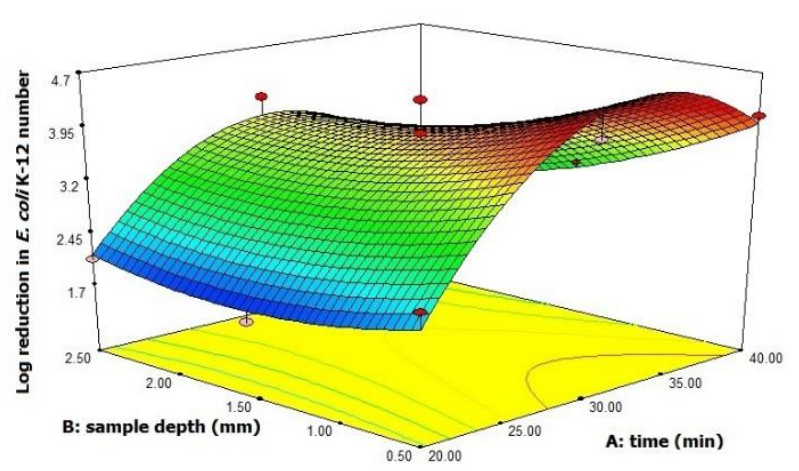

(a)

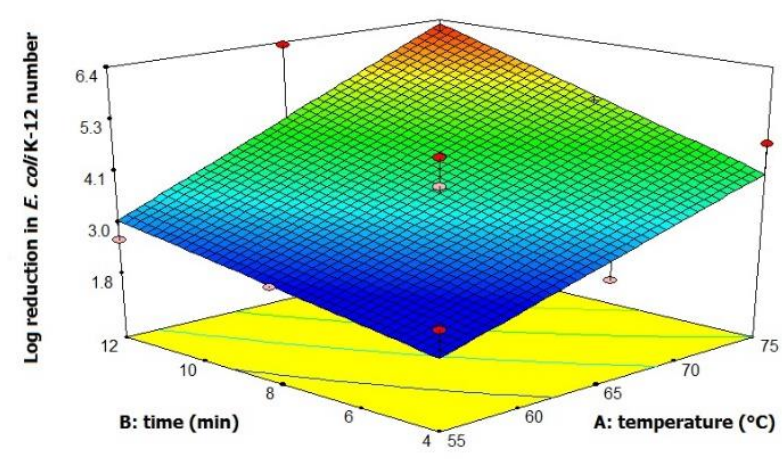

(b)

Figure 1. Response surface plot showing the interaction between a) sample depth and exposure time (UV intensity: $7.5 \mathrm{~mW} / \mathrm{cm} 2$ ) for UV-C treatment and b) temperature and time for heat treatment

In the current study, three processing conditions at selected points from the optimum region were repeated (0.5 mm sample depth; 28.23, 28.53 and 29.14 min UV-C exposure time) and validated with the maximum $13.44 \%$ convergence. The optimization study indicated that microbial reduction of $E$. coli $\mathrm{K} 12$ in onion juice was slightly lower than the $5 \mathrm{log}$ reduction performance standard recommended by FDA for juice pasteurization. Similarly, Kaya and Unluturk (2016) has subjected the freshly squeezed grape juice to $282.24 \mathrm{~mJ} / \mathrm{cm}^{2} \mathrm{UV}-\mathrm{C}$ dose by a collimated beam apparatus and $3.00 \pm 0.16 \log \mathrm{cfu} / \mathrm{mL}$ reduction was obtained for spoilage yeasts. It is directly related to the penetration of UV-C light in a liquid. Because of high absorbance coefficient specific to particulate nature of onion juice, it was speculated that a part of UV-C light might be absorbed by other compounds of onion juice and that resulted in a relatively high UV-C dose requirement in pasteurization of onion juice by UV-C irradiation.

$\mathrm{LRN}=3.83+0.52 \times \mathrm{A}-0.42 \times \mathrm{B}-0.35 \times \mathrm{AB}-1.41 \times \mathrm{A}^{2}+0.30 \times \mathrm{B}^{2}$

$\mathrm{LRN}=\mathrm{Log}$ reduction in E.coli $\mathrm{K}-12$ number 
Additionally, UV-C irradiation of onion juice under optimum conditions $(0.5 \mathrm{~mm}$ sample depth, $30 \mathrm{~min}$ irradiation, $7.5 \mathrm{~mW} / \mathrm{cm}^{2} \mathrm{UV}$ incident intensity) has resulted in a total color change $(\Delta \mathrm{E})$ value of $3.70 \pm 0.34$ i.e. well visible according to Cserhalmi et al. (2006).

\section{Determination of Conventional Heat Treatment Conditions for Pasteurized OJ}

The optimum heat treatment conditions of onion juice were investigated by FCCD experimental design considering the range of treatment temperatures (C) and time (D) between 55 to $75^{\circ} \mathrm{C}$, and 4 to $12 \mathrm{~min}$, respectively. These factors and levels were selected according to the results of a screening step (data not shown). The results of ANOVA indicated that temperature $(\mathrm{P}=0.0027)$ and time $(\mathrm{P}=0.0321)$ had significant effect on the $\log$ reduction of $E$. coli $\mathrm{K}-12$ in onion juice. The Lack-of-fit $\mathrm{P}$ value was 0.2275 . The model equation describing the log reduction of E. coli K-12 in onion juice subjected to heat treatment was given in Eq. 3. Figure 1b also demonstrates the interaction between temperature and time on the $\log$ reduction of $E$. coli $\mathrm{K}-12$ population. The maximum microbial reduction was observed between 70 to $75^{\circ} \mathrm{C}$ for 10 to $12 \mathrm{~min}$. and under these optimum heat treatment conditions, $5.94 \mathrm{log}$ reduction in E. coli K-12 was obtained.

$$
\mathrm{LRN}=3.81+1.38 \times \mathrm{C}-0.86 \times \mathrm{D}-0.26 \times \mathrm{CD}
$$

\section{$\mathrm{LRN}=\mathrm{Log}$ reduction in E.coli K-12 number}

The constructed model was confirmed by repeating 3 points from the optimum region (12 min treatment time; $75.00,74.46$ and $73.28^{\circ} \mathrm{C}$ treatment temperature) and validated with the maximum $8.16 \%$ convergence. On the other hand, heat treatment of onion juice resulted in the total color change of $1.57 \pm 0.12$ i.e. noticeable according to Cserhalmi et al. (2006).

The comparison of total color change obtained under the optimum processing conditions of UV-C or heat treatment showed that heat treatment lead to relatively low total color change. Lee and Parkin (1998) have explained this by the formation of pink pigments in the disrupted Allium tissues. It is thought that the heat treatment of onion juice may have denatured the enzymes taking role in the discoloration process and reduced the formation of pink color resulting in the relatively low $\Delta \mathrm{E}$ values in the heattreated onion juice samples.

\section{Effect of UV-C and Heat Treatment On the Physicochemical Properties of OJ}

It is well known that properties of fruit or vegetable juices such as product composition, soluble solid content, colour or general chemistry are effective on the light absorption properties of the product and have control over the efficiency of the UV-C treatment process (Koutchma et al., 2016). Therefore, quality parameters of onion juice treated with heat and UV-C irradiation were monitored in the current study.

Table 2 summarizes the physicochemical properties of control (untreated), UV-C treated and heat-treated onion juice samples which were statistically compared by one-way ANOVA using confidence interval of $95 \%$. The CIELab colour values of these three samples were significantly different with the UV-C treated samples having the highest lightness value. Kaya and Unluturk (2016) reported $L^{*}$ value of pasteurized clear grape juice increased after UV-C irradiation by a pilot-scale continuous UV system. Ibarz et al. (2005) also observed the brightening effect of UV irradiation on apple, lemon and peach juices. Similarly, Santhirasegaram et al. (2013) reported that thermal pasteurization $\left(90^{\circ} \mathrm{C}, 60 \mathrm{~s}\right)$ increased the lightness of Chokanan mango juice. The negative $\mathrm{a}^{*}$ values indicates the greenness. Caminiti et al. (2012) and Picouet et al. (2016) reported decrease in $\mathrm{a}^{*}$ values with respect to unprocessed juices after the UV-C and heat treatment, respectively. On the other hand, obtained $b^{*}$ values indicated, heat treated onion juice samples had less yellowness than the control, where UV-C irradiation enhanced the yellowness of the samples with respect to control.

No significant difference was found between the $\mathrm{pH}$ values of the investigated onion juices which were all below $\mathrm{pH} 4.6$ as adjusted by citric acid. On the other hand, total titratable acidity of UV-C treated samples was higher than the control and heat-treated onion juice samples. It was reported that citric acid has an ignorable absorbance of UV light at $254 \mathrm{~nm}$, however being a well-known ligand for metal ions, complexes of citric acid has relatively high absorbance of UV light at $254 \mathrm{~nm}$ (Seraghni et al., 2012; Mahto et al., 2014). Then, a possible photodegradation of these compounds is thought to be the reason of increase in the acidity of UV-C treated onion juice.

Koutchma (2009) reported the turbidity of juices caused by soluble and suspended solids begins with 1000 NTU for apple and other clear juices and continues with turbidity values over 4000 NTU for opaque varieties of juices. In addition, Koutchma et al. (2016) stated higher turbidity of liquid food led to less inactivation of E. coli K12. Table 4 shows control onion juice has $527.67 \pm 1.70$ NTU turbidity that is lower than that of many tropic juices listed by Koutchma et al. (2007) and higher than turbidity of lemon-melon juice blend reported as 278.50 $\pm 2.38 \mathrm{NTU}$ by Kaya et al. (2015). On the other hand, UV-C treated onion juice has approximately 2.8 times higher turbidity than the control. Similarly, Kaya et al. (2015) found turbidity of UV-C treated lemon-melon juice blend higher than that of the non-treated juice samples. Donahue et al. (2004) revealed the presence of a significant correlation between the turbidity and colour. As can be seen in Table 4 , there is a significant difference between the CIELab colour values of UV-C treated and control onion juice samples, which is thought to be a possible reason of the difference in turbidity of these mentioned samples. A similar situation is also valid for the heat-treated onion juice samples that have approximately 3 times higher turbidity values than the control.

Total soluble solids content of UV-C treated onion juice was higher than that of control (Table 2). In line with this result, Uysal and Toklucu (2011) have found the total soluble solids content of UV-C treated $(34.4 \mathrm{~J} / \mathrm{mL})$ pomegranate juice higher than the control. On the contrary, Santhirasegaram et al. (2015) reported no significant difference between the total soluble solids contents of UV$\mathrm{C}$ treated $(15,30,60 \mathrm{~min})$, heat-treated $\left(90^{\circ} \mathrm{C}, 1 \mathrm{~s}\right)$ and control Chokanan mango juices. No significant difference was determined between the densities of control and heattreated samples; whereas UV-C treated onion juice has 
higher density than the other two samples (Table 2). This slight increase in the density is compatible with the rise in turbidity and total soluble solid content of the UV-C treated onion juice.

According to Table 2, there was no significant difference between control, UV-C treated and heat-treated onion juice samples with respect to non-enzymatic browning index. The NEBI values obtained for onion juice were relatively higher than that of Chokanan mango juice reported by Santhirasegaram et al. (2015). NEBI values of Chokanan mango juice were $0.06 \pm 0.00,0.07 \pm 0.01$, and $0.13 \pm 0.01$ for control, UV treated $(30 \mathrm{~min}$ ) and heattreated juice, respectively. NEBI is the browning of juice due to Maillard reactions, subsequently causing color changes and loss of nutrients (Caminiti et al., 2011). Studies on fruit juices have shown that UV treatment may cause non-enzymatic browning on the juice as a result of photodegradation (Ibarz et al., 2005; Santhirasegaram et al., 2015). Contrarily, in the present study, UV-C treatment did not show a significant effect on NEBI. The reason for this situation will be explained by $\mathrm{pH}(\mathrm{pH}: 4.3$ in the current study), where Ibarz et al. (2005) proved that as the $\mathrm{pH}$ of juices decrease, photochemical degradation kinetics decrease, explained as the $\mathrm{pH}$ has a protective effect against irradiation. Ibarz et al. (2005) also states as the brix of lemon juice increased from 12 to 20 or $30{ }^{\circ} \mathrm{Bx}$, photochemical degradation kinetics increased. In the present study, UV-C treated samples has a relatively lower brix $\left(7.07{ }^{\circ} \mathrm{Bx}\right)$ which is also slightly higher than the control $\left(6.63^{\circ} \mathrm{Bx}\right)$. Total phenolic content of UV-C treated onion juice was lower than the control in line with the results of Chia et al. (2012). Similarly, UV-C treatment of nectarine juices of Big Top and Luciana varieties studied by Aguilar et al. (2016) resulted in a lower total phenolic content than the control.

\section{Texture Profile Analysis}

Texture profile analysis of unmarinated meat and meat marinated in untreated, UV-C or heat treated onion juice were presented in Table 3. However, control meat has the maximum hardness value among the investigated samples that indicates onion juice is a useful marinade to reduce the hardness of meat samples. Table 3 illustrates that, UV-C or heat treatment did not influence the tenderizing capability of onion juice where the hardness values of meat samples marinated in untreated, UV-C or heat treated onion juice were similar. This was not a surprising result since the $\mathrm{pH}$ values of onion juice samples did not differ significantly (data not given). It was reported that meat has higher waterholding capacity between $\mathrm{pH} 2$ to 4.5 which is directly related to the softness of meat (Belitz et al., 2004). Onion (A. сера L.) was also reported to have some proteolytic enzymes that might have acted in tenderizing of the meat samples (Lin et al., 1995). According to the one-way ANOVA test $(\mathrm{P}<0.05)$; no significant difference detected between the hardness values of control meat and marinated (in untreated, UV-C or heat treated onion juice) meat samples. Meat samples had also no significant difference with respect to adhesiveness. On the other hand, springiness of control meat samples was significantly higher than that of marinated (in untreated, UV-C or heat treated onion juice) meat samples (Table 3 ).

Table 2. The effect of uv-c and heat treatment on the physicochemical properties of onion juice

\begin{tabular}{|c|c|c|c|}
\hline Property & $\begin{array}{c}\text { Control (untreated) onion } \\
\text { juice }\end{array}$ & $\begin{array}{l}\text { UV-C treated onion } \\
\text { juice }\end{array}$ & $\begin{array}{l}\text { Heat-treated onion } \\
\text { juice } \\
\end{array}$ \\
\hline \multicolumn{4}{|l|}{ Color } \\
\hline $\mathrm{L}^{*}$ & $28.60 \pm 0.83^{\mathrm{a}}$ & $38.00 \pm 0.11^{\mathrm{b}}$ & $36.27 \pm 0.48^{\mathrm{c}}$ \\
\hline$a^{*}$ & $-0.84 \pm 0.06^{\mathrm{a}}$ & $-2.20 \pm 0.10^{b}$ & $-1.45 \pm 0.05^{\mathrm{c}}$ \\
\hline$b^{*}$ & $-0.88 \pm 0.12^{\mathrm{a}}$ & $-0.22 \pm 0.19^{b}$ & $-1.77 \pm 0.32^{c}$ \\
\hline $\mathrm{pH}$ & $4.22 \pm 0.00^{\mathrm{a}}$ & $4.23 \pm 0.00^{\mathrm{a}}$ & $4.25 \pm 0.03^{\mathrm{a}}$ \\
\hline Total titratable acidity $(\%, \mathrm{ACA})$ & $0.40 \pm 0.00^{\mathrm{a}}$ & $0.43 \pm 0.01^{\mathrm{b}}$ & $0.38 \pm 0.00^{\mathrm{c}}$ \\
\hline Turbidity (NTU) & $527.67 \pm 1.70^{\mathrm{a}}$ & $1496.33 \pm 1.25^{\mathrm{b}}$ & $1610.00 \pm 9.20^{\mathrm{c}}$ \\
\hline Total soluble solids content $\left({ }^{\circ} \mathrm{Bx}\right)$ & $6.63 \pm 0.05^{\mathrm{a}}$ & $7.07 \pm 0.05^{\mathrm{b}}$ & $6.60 \pm 0.00^{\mathrm{a}}$ \\
\hline Density $\left(\mathrm{g} / \mathrm{cm}^{3}\right)$ & $1.02 \pm 0.00^{\mathrm{a}}$ & $1.03 \pm 0.00^{\mathrm{b}}$ & $1.02 \pm 0.00^{\mathrm{a}}$ \\
\hline Non-enzymatic browning index & $0.24 \pm 0.00^{\mathrm{a}}$ & $0.24 \pm 0.01^{\mathrm{a}}$ & $0.24 \pm 0.00^{\mathrm{a}}$ \\
\hline Total phenolic content (mg/mL, GA eqv.) & $102.85 \pm 0.97^{\mathrm{a}}$ & $87.72 \pm 8.59^{b}$ & $84.43 \pm 2.62^{b}$ \\
\hline
\end{tabular}

Results were presented as means \pm standard deviation. Row values with different letters differ $(\mathrm{P}<0.05)$ significantly

Table 3. Texture profile and sensory analysis of unmarinated meat and meat marinated with untreated, uv-c or thermally treated onion juice

\begin{tabular}{ll|rrrr}
\hline & & \multicolumn{1}{c}{ CM } & \multicolumn{1}{c}{ MMUO } & \multicolumn{1}{c}{ MMTO } & \multicolumn{1}{c}{ MMHO } \\
\hline \multirow{2}{*}{ Textural profile } & Hardness (N) & $31.55 \pm 7.86^{\mathrm{a}}$ & $22.60 \pm 10.21^{\mathrm{a}}$ & $17.44 \pm 6.28^{\mathrm{a}}$ & $29.59 \pm 9.63^{\mathrm{a}}$ \\
analysis & Adhesiveness (mJ) & $2.66 \pm 0.76^{\mathrm{a}}$ & $1.33 \pm 0.97^{\mathrm{a}}$ & $1.24 \pm 0.36^{\mathrm{a}}$ & $1.76 \pm 0.73^{\mathrm{a}}$ \\
parameters & Springiness (mm) & $12.15 \pm 1.06^{\mathrm{a}}$ & $7.02 \pm 1.34^{\mathrm{b}}$ & $6.85 \pm 0.70^{\mathrm{b}}$ & $5.31 \pm 0.60^{\mathrm{b}}$ \\
& Chewiness (mJ) & $91.28 \pm 24.08^{\mathrm{a}}$ & $41.63 \pm 10.95^{\mathrm{b}}$ & $41.01 \pm 15.81^{\mathrm{b}}$ & $38.83 \pm 14.23^{\mathrm{b}}$ \\
\hline \multirow{4}{*}{ Sensory } & Overall odor & $6.60 \pm 1.93^{\mathrm{a}}$ & $5.95 \pm 2.44^{\mathrm{a}}$ & $6.05 \pm 2.36^{\mathrm{a}}$ & $6.85 \pm 2.37^{\mathrm{a}}$ \\
Properties & Overall flavor & $5.85 \pm 2.24^{\mathrm{a}}$ & $5.55 \pm 2.64^{\mathrm{a}}$ & $5.60 \pm 2.33^{\mathrm{a}}$ & $5.80 \pm 2.56^{\mathrm{a}}$ \\
& Color & $6.70 \pm 1.90^{\mathrm{a}}$ & $6.60 \pm 2.46^{\mathrm{a}}$ & $6.55 \pm 2.27^{\mathrm{a}}$ & $7.05 \pm 2.25^{\mathrm{a}}$ \\
& Chewiness & $7.10 \pm 1.89^{\mathrm{a}}$ & $6.30 \pm 1.71^{\mathrm{a}}$ & $6.75 \pm 2.36^{\mathrm{a}}$ & $7.00 \pm 2.19^{\mathrm{a}}$ \\
& Overall like & $6.55 \pm 1.60^{\mathrm{a}}$ & $6.15 \pm 2.10^{\mathrm{a}}$ & $6.10 \pm 2.17^{\mathrm{a}}$ & $6.70 \pm 2.41^{\mathrm{a}}$ \\
\hline
\end{tabular}

CM: Control meat (unmarinated), MMUO: Meat marinated in untreated onion juice, MMTO: Meat marinated in UV-C treated onion juice, MMHO: Meat marinated in heat-treated onion juice; Results were presented as means \pm standard deviation. Row values with different letters differ $(\mathrm{P}<0.05)$ significantly. 
The chewiness values showed that unmarinated meat samples (control) needed more energy to chew them to reach a steady state for swallowing. The general results of texture profile analysis (Table 3) showed that marination of meat samples in onion juice did not reduce the hardness of meat significantly, but it has successfully reduced the chewiness values that indicates the potential of tenderizing ability of onion juice in case of an optimization done for marination conditions.

\section{Sensorial Evaluation}

Sensory analysis of unmarinated meat (control) and meat marinated in untreated, UV-C or heat-treated onion juice were presented in Table 3. According to the one-way ANOVA test $(\mathrm{P}<0.05)$; there was no significant difference between the control meat and meat marinated in untreated, UV-C or heat-treated onion juice regarding to sensorial properties. Panelists gave the maximum average score to meat marinated in heat-treated onion juice for the "overall like". Meat samples marinated in onion juice (untreated, UV-C or heat treated) were not different form the control (unmarinated) with respect to any sensorial property. This was an unexpected result since, many researchers reported the formation of volatile compounds due to the Maillard reactions between Sulphur amino acids and sugar content of genus Allium as a result of heat treatment (Villière et al., 2015). It is thought that selected type of cooking method i.e. grilling may have suppressed the sense of abovementioned volatile compounds by the panelists. On the other hand, Table 3 also showed that, applying UV-C or heat treatment on onion juice did not cause negative taste sensed by the panelists which means both techniques can be used for processing of onion juice without causing an adverse effect on taste and flavor. The panelists scored the investigated sensorial properties of the control and marinated (untreated, UV-C or heat treated) meat samples in the range of 5.5 to 7.1. The score range is in line with Gibis (2007), who has marinated the meat in an oil marinade with different proportions of garlic, onion, and lemon juice. Following frying of the marinated meat, sensory test was made, and 30 panelists gave points between 4 and 6.5 over 10 to the odor and flavor of samples.

\section{Conclusions}

In this study, both UV-C and heat treatment techniques were found to be successful (under the optimized conditions) regarding the microbial food safety. The physicochemical analyses of onion juices produced under the optimized conditions suggested that UV-C treatment preserved some of the quality attributes of onion juice $\left(\mathrm{L}^{*}\right.$, $\mathrm{a}^{*}, \mathrm{~b}^{*}$ values, turbidity and total phenolic content) better than heat treatment. Marination of meat in onion juice has slightly reduced the hardness of the meat exhibiting its potential, however, to reveal the marination power of onion juice, marination parameters should be further optimized.

In this study, for the production of pasteurized onion juice, UV-C and heat treatment techniques were investigated regarding the microbial food safety, physicochemical and marination properties. RSM technique was successfully utilized for the optimization of UV-C and heat treatment conditions. The optimum UV-C treatment conditions were $0.5 \mathrm{~mm}$ sample depth, $30 \mathrm{~min}$ irradiation, $7.5 \mathrm{~mW} / \mathrm{cm}^{2} \mathrm{UV}$ incident intensity, whereas they were $75^{\circ} \mathrm{C}$ and 12 min for heat treatment of onion juice. The applied treatments showed remarkable differences in $\mathrm{L}^{*}, \mathrm{a}^{*}, \mathrm{~b}^{*}$ values, total titratable acidity, turbidity, total soluble solids content and density. Textural profile analysis of the marinated meat samples exhibited to reveal the marination power of onion juice, marination parameters should be further optimized. The UV-C or heat treatment has no negative effect on the sensorial properties of onion juice. The results of this study is believed to give idea about the selection of an appropriate pasteurization technique to onion juice producers and to the researchers for the design of a UV-C reactor suitable for onion juice pasteurization.

\section{Acknowledgements}

This work was supported by TÜBITAK with the project number TOVAG-1150981.

\section{Conflict of Interest}

The Authors declare that there are no conflicts of interest.

\section{References}

Aguilar K, Ibarz R, Garvín A, Ibarz A. 2016. Effect of UV-Vis irradiation on enzymatic activities and the physicochemical properties of nectarine juices from different varieties. LWT Food Science and Technology, 65: 969-977. https://doi.org/10.1016/j.lwt.2015.09.006

Belitz HD, Grosch W, Schieberle P. 2004. Food Chemistry. 3rd ed. New York: Springer-Verlag.

Caminiti IM, Noci F, Muñoz A, Whyte P, Morgan DJ, Cronin DA, Lyng, JG. 2011. Impact of selected combinations of nonthermal processing technologies on the quality of an apple and cranberry juice blend. Food Chemistry, 124(4): 13871392. https://doi.org/10.1016/j.foodchem.2010.07.096

Caminiti IM, Palgan I, Muñoz A, Noci F, Whyte P, Morgan DJ, Lyng JG. 2012. The effect of ultraviolet light on microbial inactivation and quality attributes of apple Juice. Food and Bioprocess Technology, 5(2): 680-686. https://doi.org/10.1007/s11947-010-0365-x

Chia SL, Rosnah S, Noranizan MA, Wan Raml WD. 2012. The effect of storage on the quality attributes of ultravioletirradiated and thermally pasteurised pineapple juices. International Food Research Journal, 19(3): 1001-1010.

Cserhalmi Z, Sass-Kiss Á, Tóth-Markus M, Lechner N. 2006. Study of pulsed electric field treated citrus juices. Innovative Food Science and Emerging Technologies, 7(1-2): 49-54. https://doi.org/10.1016/j.ifset.2005.07.001

Demir H, Yıldız MK, Becerikli İ, Unluturk S, Kaya Z. 2018. Assessing the impact of non-thermal and thermal treatment on the shelf-life of onion juice. Czech Journal of Food Sciences, 36(No. 6): 480-486. https://doi.org/10.17221/163/2018-cjfs

Demirdöven A. Effects of some electrical methods on the yield and quality characteristics in orange juice production. Ege University; 2009.

Donahue D, Canitez N, Bushway A. 2004. UV inactivation of $E$. coli $\mathrm{O} 157: \mathrm{H} 7$ in apple cider: quality, sensory and shelf-life analysis. Journal of Food Processing and Preservation, 28: 268-287. https://doi.org/10.1111/j.1745-4549.2004.23062.x 
FAOSTAT. Production share of Onions, dry by region between 1994-2014 [Internet]. 2017. Available from: http://www.fao.org/faostat/en/\#data/QC/visualize. Accession date: 03 May 2019

Ferrario M, Guerrero S, Char C. 2017. Optimisation of minimal processing variables to preserve the functional quality and colour of carrot juice by means of the response surface methodology. International Journal of Food Science \& Technology, 52(4): https://doi.org/10.1111/ijfs.13348

Gibis M. 2007. Effect of oil marinades with garlic, onion, and lemon juice on the formation of heterocyclic aromatic amines in fried beef patties. Journal of Agricultural and Food Chemistry, $55(25)$ : https://doi.org/10.1021/jf071720t

10240-10247.

Gonzalez-Saiz JM, Esteban-Diez I, Rodriguez-Tecedor S, Pizarro C. 2008. Valorization of onion waste and by-products: MCRALS applied to reveal the compositional profiles of alcoholic fermentations of onion juice monitored by near-infrared spectroscopy. Biotechnology and Bioengineering, 101(4): 776-787. https://doi.org/10.1002/bit.21939

Ibarz A, Pagán J, Panadés R, Garza S. 2005. Photochemical destruction of color compounds in fruit juices. Journal of Food Engineering, 69(2): 155-160 https://doi.org/10.1016/j.jfoodeng.2004.08.006

Kaya Z, Unluturk S. 2016. Processing of clear and turbid grape juice by a continuous flow UV system. Innovative Food Science and Emerging Technologies, 33: 282-288. https://doi.org/10.1016/j.ifset.2015.12.006

Kaya Z, Yildiz S, Ünlütürk S. 2015. Effect of UV-C irradiation and heat treatment on the shelf life stability of a lemon-melon juice blend: Multivariate statistical approach. Innovative Food Science and Emerging Technologies, 29: 230-239. https://doi.org/10.1016/j.ifset.2015.03.005

Koutchma T, Keller S, Chirtel S, Parisi B. 2004. Ultraviolet disinfection of juice products in laminar and turbulent flow reactors. Innovative Food Science and Emerging $\begin{array}{lll}\text { Technologies, } & 5(2) \text { : } & \text { 179-189. }\end{array}$ https://doi.org/10.1016/j.ifset.2004.01.004

Koutchma T, Parisi B, Patazca E. 2007. Validation of UV coiled tube reactor for fresh juices. Journal of Environmental Engineering and Science, 6(3): 319-328. https://doi.org/10.1139/s06-058

Koutchma T, Popović V, Ros-Polski V, Popielarz A. 2016. Effects of Ultraviolet Light and High-Pressure Processing on Quality and Health-Related Constituents of Fresh Juice Products. Comprehensive Reviews in Food Science and Food Safety, 15(5): 844-867. https://doi.org/10.1111/15414337.12214

Koutchma T. 2009. Advances in Ultraviolet Light Technology for Non-thermal Processing of Liquid Foods. Food and Bioprocess Technology, 2: 138-155. https://doi.org/10.1007/s11947-008-0178-3

Lee CH, Parkin KL. 1998. Relationship between thiosulfinates and pink discoloration in onion extracts, as influenced by $\mathrm{pH}$. Food Chemistry, 61(3): 345-350. https://doi.org/10.1016/S0308-8146(97)00068-X

Li S, Ma C, Gong G, Liu Z, Chang C. Xu, Z. 2016. The impact of onion juice on milk fermentation by Lactobacillus acidophilus. LWT - Food Science and Technology, 65: 543548. https://doi.org/10.1016/j.lwt.2015.08.042

Lin Y-H, Yao WH. 1995. Onion (Allium cepa L.) contains some high proteolytic activities already before germination. Botanical Bulletin Academia Sinica, 36: 81-87.
Mahto TK, Roy A, Sahoo B, Sahu SK. 2014. Citric Acid Fuctionalized Magnetic Ferrite Nanoparticles for Photocatalytic Degradation of Azo Dye. Journal of Nanoscience and Nanotechnology, 15(1): 273-280. https://doi.org/10.1166/jnn.2015.9223

Mitra J, Shrivastava SL, Rao PS. 2012. Onion dehydration: A review. Journal of Food Science and Technology, 49(3): 267277. https://doi.org/10.1007/s13197-011-0369-1

Picouet PA, Sárraga C, Cofán S, Belletti N, Dolors Guàrdia M. 2015. Effects of thermal and high-pressure treatments on the carotene content, microbiological safety and sensory properties of acidified and of non-acidified carrot juice. LWT - Food Science and Technology, 62(1): 920-926. https://doi.org/10.1016/j.lwt.2014.07.027

Santhirasegaram V, Razali Z, George DS, Somasundram C. 2015. Comparison of UV-C treatment and thermal pasteurization on quality of Chokanan mango (Mangifera indica L.) juice. Food and Bioproducts Processing, 94(April): 313-321. https://doi.org/10.1016/j.fbp.2014.03.011

Seraghni N, Belattar S, Mameri Y, Debbache N, Sehili T. 2012. Fe(III)-Citrate-Complex-Induced Photooxidation of 3Methylphenol in Aqueous Solution. International Journal of Photoenergy, 2012(November): 1-10. https://doi.org/10.1155/2012/630425

Shah, NAK, Shamsudin R, Abdul Rahman R, Adzahan N. 2016. Fruit Juice Production Using Ultraviolet Pasteurization: A Review. $\quad$ Beverages, $2(3)$ : 22. https://doi.org/10.3390/beverages2030022

Sun T, Powers JR, Tang J. 2007. Evaluation of the antioxidant activity of asparagus, broccoli and their juices. Food Chemistry, 105(1): 101-106. https://doi.org/10.1016/j.foodchem.2007.03.048

Tran MTT, Farid M. 2004. Ultraviolet treatment of orange juice. Innovative Food Science and Emerging Technologies, 5(4): 495-502. https://doi.org/10.1016/j.ifset.2004.08.002

Turtoi M, Borda D. 2013. Ultraviolet light efficacy for microbial inactivation on fruit juices, nectars and apple cider. Journal of Agroalimentary Processes and Technologies, 19(1): 130140.

Unluturk S, Atilgan MR, Baysal AH, Tari C. 2008. Use of UV-C radiation as a non-thermal process for liquid egg products (LEP). Journal of Food Engineering, 85(4): 561-568. https://doi.org/10.1016/j.jfoodeng.2007.08.017

Unluturk S, Atilgan MR. 2014. UV-C irradiation of freshly squeezed grape juice and modeling inactivation kinetics. Journal of Food Process Engineering, 37(4): 438-449. https://doi.org/10.1111/jfpe.12099

Uysal Pala Ç, Kirca Toklucu A. 2011. Effect of UV-C light on anthocyanin content and other quality parameters of pomegranate juice. Journal of Food Composition and Analysis, 24(6): 790-795. https://doi.org/10.1016/j.jfca.2011.01.003

Uysal Pala Ç, Kirca Toklucu A. 2013. Microbial, physicochemical and sensory properties of UV-C processed orange juice and its microbial stability during refrigerated storage. LWT - Food Science and Technology, 50(2): 426431. https://doi.org/10.1016/j.lwt.2012.09.001

Villière A, Le Roy S, Fillonneau C, Guillet F, Falquerho H, Boussely S, Prost C. 2015. Evaluation of aroma profile differences between sué, sautéed, and pan-fried onions using an innovative olfactometric approach. Flavour, 4(1): 24. https://doi.org/10.1186/s13411-015-0034-0

Wu JSB, Chen S-C. 2011. Handbook of Vegetables and Vegetable Processing. Sinha NK, editor. Wiley-Blackwell; $772 \mathrm{p}$. 